\title{
The impact of the Defeat Depression campaign
}

\author{
Martin Orrell, Elizabeth Collins, Bob Baldwin, and Cornelius Katona
}

\begin{abstract}
A postal questionnalre survey of nearty a thousand doctors investigated their awareness of the Defeat Depression campaign. Nearty all the consultant poychlatists had heard of the campaign compared to less than half of the geriaticicians and the general practitioners (GPS). Just over half of the psychiatry trainees had heard of the campaign. GPs who had not heard of the campaign were also less likely to continue antidepressant treatment beyond three months after recovery, less famillar with the psychological theraples, and less conildent about treating depression in the elderly. The campalon may benefit from an increased emphasis on doctors other than poychiatrists.
\end{abstract}

The overall annual cost of depression in England and Wales has recently been estimated to be $£ 3$ billion (Kind \& Sorensen, 1993). A large opinion poll in December 1991 found that only $16 \%$ of the public felt that people with depression should be offered antidepressants (Vize \& Priest, 1993). Many GPs fail to treat depression in the elderly (Macdonald, 1986) and are reluctant to keep patients on antidepressants for more than 3 months even though maintenance treatment with antidepressants considerably reduces the risk of relapse (Orrell et al 1995a). This suggests a need for a better awareness of treatment for depression among GPs. In January 1992 the Royal Colleges of Psychiatrists and General Practitioners embarked on a public campaign known as 'Defeat Depression' which aimed to increase public and professional awareness of depression and its treatment (Vize \& Priest, 1993). For the Defeat Depression campaign to have any prospect of real success, doctors and the general public need to be made aware of it and also understand what it is about. As part of a larger study (Orrell et al, 1995a) (linked with the Defeat Depression campaign) which evaluated doctors' attitudes to and management of depression in the elderly we also assessed their awareness of the Defeat Depression campaign.

\section{The study}

The study was carried out in the second half of 1992, at least six months after the campaign began in January 1992 . The 952 doctors surveyed included: 667 GPs (from five nationally representative catchment areas); 143 geriatricians; 96 oldage psychiatrists (selected from national lists), and 46 trainee psychiatrists (from a large London training scheme). These groups were selected as they were all likely to be clinically involved with a considerable number of depressed patients. All doctors were sent a postal questionnaire about depression with a stamped addressed envelope enclosed for return.

\section{Findings}

We received $602(63 \%)$ completed replies (the response rate ranged from $61 \%$ to $75 \%$ ). Overall, $282(48.7 \%)$ doctors had heard of the campaign. Nearly all (94.3\%) of the old-age psychiatrists had heard of the Defeat Depression campaign, compared to only $57.1 \%$ of psychiatry trainees, $40.7 \%$ of geriatricians and $41.3 \%$ of GPs. There were no associations between age, sex or area of practice and knowledge of the campaign. However, geriatricians $\left(\chi^{2}=4.44, P=0.04\right)$, psychiatry trainees (Fisher's exact test, $P=0.02$ ) and GPs $\left(\chi^{2}=4.18, P=0.04\right)$ who felt confident in their ability to treat depression were also more likely to be aware of the campaign. General practitioners who had not heard of the campaign were less likely to continue antidepressant treatment for more than three months $\left(\chi^{2}=5.86, P=0.02\right)$ and were also less familiar with the psychological treatments available for depression $\left(\chi^{2}=9.68\right.$, $P=0.002$ ).

\section{Comment}

Awareness does not guarantee effectiveness but it is a necessary starting point. As expected, since it is regularly highlighted in the Psychiatric Bulletin of the Royal College of Psychiatrists, the vast majority of psychiatrists had heard of the Defeat Depression campaign. However, the majority of geriatricians and GPs had not heard of it and neither had many of the psychiatry trainees. Lack of awareness about the campaign was associated 
with a lack of confidence in treating depression. GPs who were unaware of the campaign also appeared to be less knowledgeable about the management of depression. To some extent, at least in its first year, the campaign may have been preaching to the converted rather than reaching the majority of doctors in primary care or geriatric medicine, many of whom also have a clear and expressed need for more training in the treatment of depression in the elderly (Collins et al, 1995; Orrell et al, 1995b). However, it is also possible to argue that $40 \%$ awareness among GPs is not a bad start and that awareness should be increasing as the campaign continues. Nevertheless, there is a danger that such campaigns may begin to lose momentum after a few years. The Defeat Depression campaign is undoubtedly an important initiative but it may need to reconsider its strategy to ralse awareness and focus training more on groups other than psychiatrists. More recently, two training packages for GP trainers have been launched as well as other educational material. We intend to do a follow up study to investigate how awareness of the campaign has changed over time. In addition, a further study is in progress which will look at the impact of the campaign on GP trainees.

\section{Acknowledgement}

This study was supported by a grant from Dista Psychiatric Education Services.

\section{References}

Coluns, E., KATONA, C. \& ORREu, M. W. (1995) The Management of Depression in the Elderly by General Practitioners: 2 attitudes to ageing and factors afiecting practice. Family Practice, 12, 1, 12-17.

Kind, P. \& SOREnsen, J. (1993) The costs of depression. International Journal of Clinical Psychopharmacology. 7. 191-195.

MACDONALD, A. (1986) Do general practitioners 'miss' depression in elderly patients. British Medical Joumal 292, 1365-1367.

OrReu, M. W., Counns, E., Shergil, S., et al (1995a) The Management of Depresston in the Elderty by General Practitioners: 1 use of antidepressants. Family Practice. 12. 1, 5-11.

-, BALDWIN, B.. Counns, E., et al (1995b) A National Survey of the Management of Depression by Gerlatriclans and Old Age Psychiatrists. International Joumal of Gerlatric Psychiatry. 10, 457-467.

VIZE, C., \& PRIEST, R. (1993) Defeat Depression Campaign attitudes towards depression. Psychiatric Bulletin, 17. 573-574.

*Martin W. Orrell, Senior Lecturer in Psychiatry of the Elderly. University College London Medical School: Bob Baldwin, Consultant Psychiatrist for the Elderly. York House, Manchester Royal Infirmary, Manchester M13 9BX; Elizabeth Collins, Research Worker, Princess Alexandra Hospital, Harlow, Essex, Cornelius Katona, Professor of Psychiatry of the Elderly. University College London Medical School, London WC1.

*Correspondence: Dr M. Orrell, Department of Psychiatry, Princess Alexandra Hospital Harlow, Essex CM20 19X. 